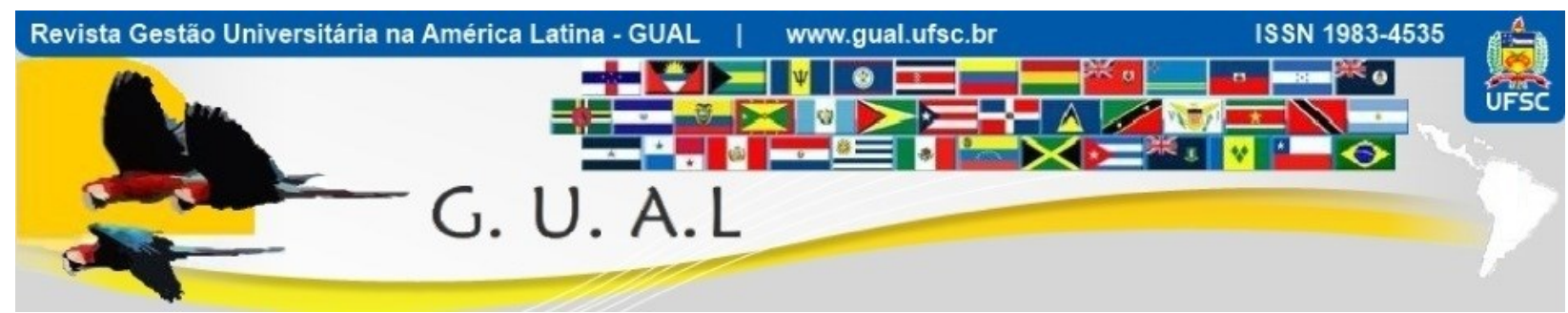

DOI: https://doi.org/10.5007/1983-4535.2021.e80173

\title{
A MUNICIPALIZAÇÃO DO ENSINO SUPERIOR NO BRASIL: UM ESTUDO DE MULTICASOS NA DIMENSÃO ESTRUTURAL E DE GESTÃO DE PESSOAS
}

\section{THE MUNICIPALIZATION OF HIGHER EDUCATION IN BRAZIL: A STUDY OF MULTICLES IN STRUCTURAL DIMENSION AND PEOPLE MANAGEMENT}

\author{
Cibelli de Medeiros Pickler, Mestre \\ https://orcid.org/0000-0001-7187-1020 \\ cibellipickler@gmail.com \\ Faculdade Municipal de Palhoça $\mid$ Curso de Administração \\ Palhoça | Santa Catarina | Brasil \\ Fabiana Elisa Boff Silveira, Mestre \\ https://orcid.org/0000-0002-9425-3652 \\ fboff1030@gmail.com \\ Faculdade Municipal de Palhoça $\mid$ Curso de Administração \\ Palhoça | Santa Catarina | Brasil \\ Irineu Manoel de Souza, Doutor \\ https://orcid.org/0000-0002-3640-0853 \\ irineu.manoel@ufsc.br \\ Universidade Federal de Santa Catarina | Centro Socioeconômico \\ Florianópolis | Santa Catarina | Brasil
}

Recebido em 25/março/2021

Aprovado em 09/julho/2021

Publicado em 01/setembro/2021

Sistema de Avaliação: Double Blind Review

Esta obra está sob uma Licença Creative Commons Atribuição-Uso. 


\title{
RESUMO
}

A municipalização do ensino superior é realidade no Brasil, mas se constitui em um mecanismo pouco estruturado, dependente da capacidade de arrecadação para obter maior autonomia administrativa e financeira do município. O objetivo do artigo é compreender a dimensão estrutural e de gestão de pessoas das instituições de ensino superior públicas municipais e gratuitas no Brasil. Para o cumprimento do objetivo, utilizou-se os métodos de pesquisa bibliográfico e documental, abordagem qualitativa e pela análise explicativa e descritiva dos dados. Dessa forma, o estudo buscou responder como se compõem as estruturas legal e funcional de quatro IMES (Instituição Municipal de Ensino Superior), USJ, FMP, FAIBI e FACELI, enquadradas como públicas e gratuitas. Os resultados do estudo permitiram identificar, dentre outros aspectos, que a FMP é uma autarquia mantida pela prefeitura enquanto as demais IMES são mantidas por fundações educacionais; o USJ configura como um centro universitário representado pelo reitor e as demais são enquadradas como Faculdades retratadas por seus diretores; a FAIBI é a única que não possui um sistema de cotas para o ingresso do aluno na instituição; a FACELI e a FMP possuem o plano de cargos e carreira instituídos, porém a FACELI apresenta ações mais próximas de uma gestão estratégica de pessoas por competência, vigorando o Plano de Cargos, Carreira e Remunerações tanto para o corpo docente quanto para os técnicos administrativos, assim como o sistema de Avaliação de Desempenho voltado para competências.

Palavras-chave: Municipalização. Estrutura das IMES. Gestão de Pessoas.

\begin{abstract}
The municipalization of higher education is a reality in Brazil, but it is a poorly structured mechanism, dependent on the collection capacity to obtain greater administrative and financial autonomy for the municipality. The objective of the article is to understand the structural and people management dimension of municipal and free public higher education institutions in Brazil. To achieve the objective, bibliographic and documentary research methods were used, with a qualitative approach and through explanatory and descriptive data analysis. Thus, the study sought to answer how the legal and functional structures of four IMES (Municipal Institution of Higher Education), USJ, FMP, FAIBI and FACELI, are classified as public and free. The results of the study made it possible to identify, among other aspects, that the FMP is an autarchy maintained by the city while the other IMES are maintained by educational foundations; the USJ is configured as a university center represented by the dean and the others are classified as Faculties portrayed by its directors; FAIBI is the only one that does not have a quota system for students to enter the institution; FACELI and FMP have the job and career plan in place, however FACELI has actions closer to strategic management of people by competence, with the Positions, Career and Compensation Plan in place for both faculty and administrative technicians, as well as the performance evaluation system focused on competencies.
\end{abstract}

Keywords: Municipalization. Structure of IMES. People Management. 


\section{INTRODUÇÃO}

As práticas de interação social por meio das tecnologias foram aceleradas em decorrência da pandemia pela COVID-19, transformando a maneira como as instituições de ensino presenciais ofertam educação, forçando-as a se readequarem e flexibilizarem seus sistemas de ensinagem e aprendizagem. As instituições de ensino superior públicas no Brasil atendendo às novas diretrizes do Ministério da Educação quanto ao novo modelo a distância a ser adotado em função da pandemia, pressionou, mesmo as mais burocratizadas, um processo decisório para inserção e adaptação às tecnologias na condução de aulas em tempo real. As Universidades Federais, em sua maioria, decidiram iniciar as aulas remotamente a partir do segundo semestre de 2020. A complexidade estrutural dessas instituições, fez com que um moroso movimento de diálogo com a comunidade acadêmica fosse deflagrado para se chegar a um consenso e migrar para o ensino EAD (CARVALHO, 2020).

Nesse sentido, idealiza-se que as instituições de ensino superior públicas municipais configurem estruturas mais enxutas, haja vista que os municípios atuam como instrumentos para a democratização e eficiência na entrega do ensino por estarem mais próximos das necessidades reais da sociedade. Nessa mesma linha, as instituições de ensino superior municipais surgiram mediante a proposta de um maior fortalecimento do ensino superior no país, para uma possibilidade de levar o ensino para o interior das Unidades da Federação.

No Brasil, o número de instituições de ensino superior, segundo os dados do E-Mec em 2018, é de 3.249 IES (Instituições de Ensino Superior), sendo que dessas, 2.903 são de natureza privada e 346 de natureza pública. No que diz respeito à organização acadêmica das IES públicas, tem-se 113 Universidades, 13 Centros Universitários, 151 enquadradas como Faculdades e 69 vinculadas a outros enquadramentos (E-MEC, 2020).

No que concerne as instituições públicas, das 346 IES públicas, 36 são enquadradas como Pessoa Jurídica de Direito Público Municipal em conformidade com o E-Mec (2020), cabendo desvendar quais dessas IES ofertam seus cursos gratuitamente. Assim, a pergunta de pesquisa que se constrói é: Como se compõe a dimensão estrutural e a área de Gestão de Pessoas das IES públicas municipais e gratuitas no Brasil?

Para responder ao problema de pesquisa, o estudo tem como objetivo compreender a dimensão estrutural e de gestão de pessoas das instituições de ensino superior públicas municipais e gratuitas do Brasil. 
O estudo se justifica tendo em vista o pouco conhecimento gerado e publicado no âmbito dessas instituições. Também, no que concerne ao estudo da área de gestão de pessoas, tem-se algumas questões da própria gestão municipal, como a baixa qualificação do corpo técnico de funcionários, que requer a formação de competências básicas para assegurar a qualidade dos serviços prestados. Outro ponto a considerar trata da dependência da transferência de recursos que provêm da arrecadação do município, sendo que o Ensino Superior não engloba o percentual constitucional (25\%), que devem ser aplicados à Educação Básica. Por isso, a municipalização do ensino superior ainda é tema de constante discussão no meio social e político, margeando a discussão sobre o papel do município como mantenedor desse nível de educação. E por fim, a limitação de recursos destinados ao funcionamento das IES impede a estruturação da área de gestão de pessoas em seu papel mais estratégico, sendo importante o estudo para compreender como estão estruturadas as áreas de gestão de pessoas nessas diferentes instituições, mas que contemplam o mesmo escopo e ordenamento jurídico, ou seja, públicas municipais e gratuitas.

O artigo está estruturado a partir desta introdução, apresentando o tema, problema de pesquisa e objetivo; do referencial teórico, discorrendo acerca da municipalização do ensino superior e a área de gestão de pessoas nas IES públicas; dos procedimentos metodológicos utilizados no desenvolvimento do estudo; da apresentação dos dados, contemplando a caracterização das IMES e descrição das estruturas das IMES públicas e gratuitas; da análise e discussões; e por último, da conclusão, retomando os elementos auges identificados nos decorrer da pesquisa que permitiram alcançar o objetivo e responder ao problema.

\section{REFERENCIAL TEÓRICO}

Neste capítulo, apresentam-se os tópicos que contemplam a base teórica para o cumprimento do objetivo do estudo, focando na compreensão das instituições públicas municipais de ensino superior no Brasil e na área de gestão de pessoas nas IES públicas.

\subsection{AS INSTITUIÇÕES PÚBLICAS MUNICIPAIS DE ENSINO SUPERIOR NO BRASIL}

Com a promulgação da Constituição Federal (CF) de 1988 o processo de descentralização se construiu imperado pelo Regime de Colaboração entre a União, os Estados, o Distrito Federal e os Municípios, responsáveis pela organização dos sistemas de ensino. Com isso, definiu-se uma tendência de maior autonomia dos municípios na oferta do 
ensino. Na década de 90 com o PDRAE (Plano Diretor da Reforma do Aparelho do Estado) vários objetivos e diretrizes foram estabelecidos para que o processo de descentralização pudesse sair do papel constitucional, para então, estabilizar e promover o crescimento econômico e reduzir as desigualdades sociais.

A CF de 1988 possibilitou aos Municípios criarem seus próprios sistemas de ensino, atribuindo autonomia relativa na formulação de políticas educacionais, em específico para a Educação Infantil e o Ensino Fundamental (SOUZA; FARIA, 2004). Dessa forma, os municípios deveriam sanar todas as necessidades em primeira instancia da Educação Infantil, depois do Ensino Fundamental, assim de forma progressiva poder-se-ia alcançar a oferta de ensino em sua plenitude, oportunizando o ensino superior.

Para tanto, a Lei de Diretrizes e Bases da Educação Nacional (LDB), Lei n ${ }^{\circ} 9.394$ de 20 de dezembro de 1996, refletiu as diretrizes de descentralização e democratização delineadas pela CF de 1988 e pela Reforma Gerencial destacada no PDRAE de 1995, prevendo de forma clara as competências dos municípios no que tange a instituição de seus próprios sistemas de ensino (MACHADO; DIÓGENES; BEZERRA, 2013). O art. 11 da referida Lei, diz que os municípios serão incumbidos de organizar, manter e desenvolver os órgãos e instituições oficiais, devendo integrá-los às políticas e planos da União e dos Estados.

Diante desse fato, ressalta-se que a LDB (1996) deixa margem para a oferta do ensino superior pelos municípios, desde que, os níveis de ensino de sua competência estejam plenamente atendidos e que os percentuais destinados para a educação determinados pela $\mathrm{CF} / 88$, ou seja, $25 \%$ dos impostos e transferências, sejam aplicados na manutenção e desenvolvimento do sistema prioritário.

De acordo com Neves (2018), o impulsionamento para o surgimento das municipais teve por objetivo o alcance da interiorização da educação, levando o ensino superior para localidades fora das capitais por meio das Instituições Municipais de Ensino Superior (IMES), pois com a formação de profissionais de nível superior na região, o município possibilita formar mão de obra qualificada e torna mais legítimo que os profissionais se fixem em sua região natal, agregando valor à economia local.

Pelo viés da arrecadação, há de se pensar em novos mecanismos para a municipalização do ensino superior, não apenas na cobrança de mensalidades, mas também na participação colaborativa dos recursos federais e estaduais para este fim. Pois conforme 
apregoa a AIMES-SP (2020), as instituições municipais de ensino superior não devem ser deficitárias, pois necessitam de razoável saúde financeira para manter suas atividades com qualidade. $\mathrm{O}$ excedente acumulado retorna à comunidade acadêmica na forma de investimentos.

Desse modo, os municípios possuem papel preponderante na descentralização, haja vista uma menor hierarquia e procedimentos mais simplificados (GUIMARÃES, 1993), na qual conferem maior autonomia às IMES para atender com eficácia e adequando as necessidades da população local. E, em se tratando do ensino superior, dando a oportunidade de acesso àqueles que não teriam condições de fazer uma universidade Estadual ou Federal gratuitamente, devido ao alto índice de candidato por vaga nessas instituições. Em contrapartida, discute-se atualmente o perigoso processo de mercantilização do ensino, a expansão da educação a distância, que em qualquer lugar, a qualquer tempo, e utilizando recursos tecnológicos variados fazem com que os alunos tenham acesso ao ensino superior a um valor de mensalidade reduzido, sendo oportuno identificar as alternativas que estas instituições municipais representam.

\subsection{A ÁREA DE GESTÃO DE PESSOAS NAS IES PÚBLICAS}

A estrutura de Gestão de Pessoas (GP) passa pelo tradicional departamento de pessoal da década de 1950, pela divisão de relações industriais na década de 1960, à recente área de recursos humanos de forma mais estratégica. Atualmente, as significativas mudanças apontam para um inovador modelo de gestão de pessoas, que passará a participar na formulação e elaboração das estratégias da empresa, pois elas dependem cada vez mais das pessoas em todos os níveis (TACHIZAWA; FERREIRA; FORTUNA, 2006; MARRAS; 2016).

É possível traçar um novo modelo de gestão de pessoas voltado para a elaboração de políticas humanas da organização, mais estratégico, a partir de mecanismos como: a) Planejamento de RH; b) Gestão de Competências; c) Capacitação Continuada com base na competência; d) Avaliação de desempenho e de competências (CAMÕES; PANDOJA; BERGUE, 2010). Não se trata de um processo racional fechado, mas aberto e interdependente, partindo da influência do ambiente sobre a IES.

Com o Decreto 5.707/2006 revogado pelo decreto $\mathrm{n}^{\mathrm{o}} 9.991$ de 28 de agosto de 2019, impôs-se uma mudança do modelo de gestão tradicional para um modelo de gestão de pessoas por competências na administração pública, em especial nas universidades federais no Brasil, 


\section{A MUNICIPALIZAÇÃO DO ENSINO SUPERIOR NO BRASIL: UM ESTUDO DE MULTICASOS NA \\ DIMENSÃO ESTRUTURAL E DE GESTÃO DE PESSOAS \\ DOI: https://doi.org/10.5007/1983-4535.2021.e80173}

envolvendo a multiplicidade e a complexidade de componentes como carreira, reconhecimento, avaliação $360^{\circ}$, planejamento de sucessão, ou seja, vai muito além de capacitação permanente e contínua (SILVA, 2019).

A tendência aponta para a reformulação das IES para um modelo de gestão por competências, haja vista que a imposição por atos legais vem forçando as IES Federais a readequarem seus processos de gestão de pessoas, servindo como referencial. Ainda que, percebe-se que as práticas de GP adotadas no Brasil desde os anos 80 possui como base a estrutura de cargos, dando ênfase a ocupação de cargos com crescente grau de hierarquia e responsabilidade, a partir do organograma da organização (ALBUQUERQUE; OLIVEIRA, 2001; SILVA, 2009; ROCHA; SHINYASHIKI; PASSADOR, 2012). Neste sentido, em muitas organizações públicas a área de gestão de pessoal ainda se dedica às atividades de folha de pagamento, benefícios da aposentadoria, propondo Leis, regras e regulamentos, e esporadicamente ações pontuais de treinamento (MAGALHÃES ET AL, 2010; CAMÕES; PANDOJA; BERGUE (2010).

O modelo público não consegue resolver problemas que demandam de estruturas mais orgânicas, como a descentralização das decisões salariais e o incentivo ao desenvolvimento individual, ou seja, relega para um segundo plano as atividades estratégicas, como o planejamento de ações, definição de políticas sobre a contratação, capacitação e remuneração de pessoal, ou ainda a realização do trabalho com o adequado desempenho (SILVA, 2009; CAMÕES; PANDOJA; BERGUE, 2010; SILVA, 2019).

Para Magalhães et al (2010), as IES públicas são semelhantes aos demais órgãos públicos, tendo estruturas burocráticas profissionalizadas, ou seja, voltadas para a padronização de habilidades e ênfase na autoridade. Apresentam também uma estrutura democrática, no que tange os docentes, tendo em vista que controlam seu próprio trabalho, além de buscarem o controle coletivo sobre as decisões administrativas que os afetam, indicando os próprios pares para realizar parte do trabalho administrativo, participando e presidindo colegiados, ocupando cargos de chefia, o que garante certo controle sobre as decisões que influenciam seu trabalho. Por isso, acaba-se não dando atenção para o desenvolvimento da área de GP nesse tipo de instituição.

A gestão das instituições de ensino superior não deve fugir da construção de uma nova forma de gestão de pessoas, haja vista que as IES são formadas por um conjunto de pessoas no qual as relações sociais e interpessoais transcendem as estruturas do modelo racional 
burocrático. Por isso, são ditas organizações complexas, pela especialização das atividades e pela execução de tarefas múltiplas, que embora inter-relacionadas têm características específicas que as diferem de outras organizações (SOUZA, 2009; SOUZA; KOBIYAMA, 2010).

As organizações do setor público, incluindo-se as Instituições Municipais de Ensino Superior Públicas, gradativamente vêm experimentando maiores pressões da sociedade no sentido de prestarem melhores serviços, de forma mais eficiente e com maior transparência. Assim, a demanda por instituições mais flexíveis e mutáveis não se vê restrita apenas aos círculos da iniciativa privada, atingindo também as IES do poder público. Essas expectativas esbarram nas estruturas funcionais burocráticas e inflexíveis comuns às instituições públicas brasileiras. Dessa forma, a implantação de um novo modelo de gestão de pessoas com base no conceito de competência nas IES pode auxiliar no processo de mudança da cultura organizacional vigente no setor público, de tal forma que as ferramentas de RH podem ser eficazes em promover o aumento da flexibilidade e eficiência almejadas pela sociedade (ROCHA; SHINYASHIKI; PASSADOR, 2012).

Assim, a política de Gestão de Pessoas para IES no que condiz com a dimensão humana, deve considerar ações de aprendizagem contínua dos técnicos e docentes; na aprendizagem e compartilhamento do conhecimento, criando-se uma memória institucional a partir de sistemas de informações gerenciais, possibilitando o aprendizado coletivo; nos planos de reconhecimento e recompensa, valorizando docentes, técnicos e estudantes; e estímulos à criatividade e inovação, postura importante no ambiente educacional (SOUZA, 2009; SOUZA; KOBIYAMA, 2010).

Dessa forma, o processo de indução à municipalização das instituições de ensino superior não considera a questão dos recursos humanos em condições de gerir, com sucesso, um sistema de ensino, conforme apregoa (MOTA, 2007). As IMES possuem autonomia para construir, manter ou equipar suas estruturas físicas, para alocar professores, diretores e funcionários. Contudo, entende-se que gerir a educação municipal superior seja mais que isso.

\section{PROCEDIMENTOS METODOLÓGICOS}

O estudo foi desenvolvido a partir de uma pesquisa de natureza aplicada; com uma abordagem do problema qualitativa; com objetivos descritivos e explicativos e; pelos 
procedimentos técnicos como o bibliográfico, documental, levantamento de dados e estudo de multicascos.

A pesquisa aplicada objetiva gerar conhecimentos para aplicação prática dirigida à solução de problemas singulares que ocorrem na realidade (LAKATOS; MARCONI, 2013). Ela se identifica com o presente artigo à medida que se buscou identificar a dimensão estrutural das IMES e a área de Gestão de Pessoas dessas instituições públicas e gratuitas.

A abordagem do problema do artigo dá-se por meio de uma pesquisa qualitativa. É uma forma de entender o significado que os indivíduos de um determinado grupo atribuem a um problema social (CRESWELL, 2010). Uma vez que o presente artigo oferece uma análise dos documentos, leis e quadros gerados a partir dos dados coletados, tem-se uma pesquisa com métodos qualitativos.

Quanto aos seus objetivos esse artigo possui uma pesquisa explicativa, pois, desenvolve ações com o intuito de explicar a sociedade questões que envolvem determinado fenômeno (BOENTE; BRAGA, 2004). Pode-se verificar essa questão no levantamento das 36 IMES no banco de dados do E-Mec (2020), em que foram utilizados os filtros do sistema para identificar as IES públicas e municipais no Brasil. Desse total, buscou-se nos sítios eletrônicos, documentos e legislações de cada uma quanto à cobrança de mensalidades ou gratuidade dos cursos. Dessa maneira, somente 04 se enquadram na oferta do ensino gratuito, esse fenômeno é explicado haja vista o impedimento constitucional para as IES criadas após a promulgação em 1988.

Também quanto aos objetivos, o presente artigo é descritivo, visando descrever as características de determinada população ou fenômeno ou estabelecendo relações entre variáveis. Assume, em geral, a forma de Levantamento, pois registra, analisa e correlaciona fatos ou fenômenos sem manipulá-los, procura apresentar com precisão a frequência com que os fenômenos ocorrem, ou até relacionando com outros, sua natureza e características (CERVO; BERVIAN; DA SILVA, 2007). Pode-se perceber essa questão no estudo com os Quadros 3 e 4, que apresentam a estrutura legal e de gestão de pessoas das IMES estudadas, sistematizando as características observadas de cada uma após o levantamento dos dados.

Quanto aos procedimentos técnicos a pesquisa é bibliográfica, ou seja, foi elaborada a partir de material já publicado, constituído de livros, artigos de periódicos e atualmente com material disponibilizado na Internet; documental, que são fontes de coletas de dados restritas a documentos, escritos ou não, denominada de fonte primária, no qual se utilizou documentos 
públicos das IMES (PDI, Estatuto, Regimento Geral, Plano de Cargos e salários e Leis) (LAKATOS; MARCONI, 2013); e um estudo multicasos pois envolve o estudo que carrega uma base antifundamentalista e interpretativista, explorando um sistema limitado de um ou múltiplos casos. $\mathrm{O}$ caso pode ser interpretado como um evento, uma atividade ou indivíduos, relacionando tempo e espaço (CRESWELL, 2010).

A presente pesquisa trata do universo de quatro instituições de ensino que possuem as mesmas características, ou seja, instituições de Natureza Jurídica: Pessoa Jurídica de Direito Público Municipal; possuem o credenciamento como sendo Presencial - Superior; de categoria pública, administrativa, municipal e gratuita, que são: o Centro Universitário Municipal de São José (USJ); a Faculdade de Ensino Superior de Linhares (FACELI); a Faculdade de Filosofia, Ciências e Letras de Ibitinga (FAIBI); e a Faculdade Municipal de Palhoça (FMP). Com esse corte, universo, população e amostra apresentam-se os mesmos.

Os dados foram coletados no sítio do E-Mec e a partir dos PDI's - Plano de Desenvolvimento Institucional disponíveis nos sítios das instituições anteriormente citadas. Bem como os documentos disponíveis como: Lei de Criação; PDI, Estatuto entre outros documentos relevantes para a pesquisa encontrados no sítio das IES.

\section{APRESENTAÇÃO DOS DADOS}

Neste capítulo, buscou-se descrever os dados coletados no estudo, iniciando pela caracterização das IMES no Brasil, na qual permitiu identificar as IMES públicas e gratuitas, e posteriormente a descrição de cada IMES objeto de pesquisa.

\subsection{CARACTERIZAÇÃO DAS IMES NO BRASIL}

As IMES no Brasil são resultantes de um processo de democratização do ensino superior. Existem 36 IMES enquadradas como Pessoa Jurídica de Direito Público Municipal de acordo com os dados do E-Mec (2020). Como a maior parte dessas IES foram criadas por Lei municipal anterior à $\mathrm{CF}$ de 88 , permite a cobrança de mensalidades como forma parcial ou integral de seu custeio, sustentadas no argumento de que a Administração Pública pode cobrar o fornecimento do ensino na forma de taxa ou tarifa, que segundo Neto (2018) serve como uma contraprestação pecuniária para a continuidade dos serviços públicos.

A CF/88 em seu artigo 206, inciso IV, diz que as IES públicas oficiais oferecerão ensino gratuito. Todavia, no artigo 242 dispõe que o art. 206, IV, não se aplica às IES oficiais 
criadas por Lei estadual ou municipal e existentes na data da promulgação da constituição. $\mathrm{Ou}$ seja, atualmente as IMES que cobram mensalidades foram criadas antes da promulgação da CF/88 (BRASIL, 1988).

Com isso, somente 4 IES possuem o perfil de instituições de ensino públicas, municipais e gratuitas, que são: o Centro Universitário Municipal de São José (USJ); a Faculdade de Ensino Superior de Linhares (FACELI); a Faculdade de Filosofia, Ciências e Letras de Ibitinga (FAIBI); e a Faculdade Municipal de Palhoça (FMP). O Quadro 2 mostra as instituições, sigla, Unidade da Federação, cursos ofertados e ano de fundação. Cabe salientar que elas não cobram mensalidades.

Quadro 1 IMES públicas, municipais e gratuitas no Brasil

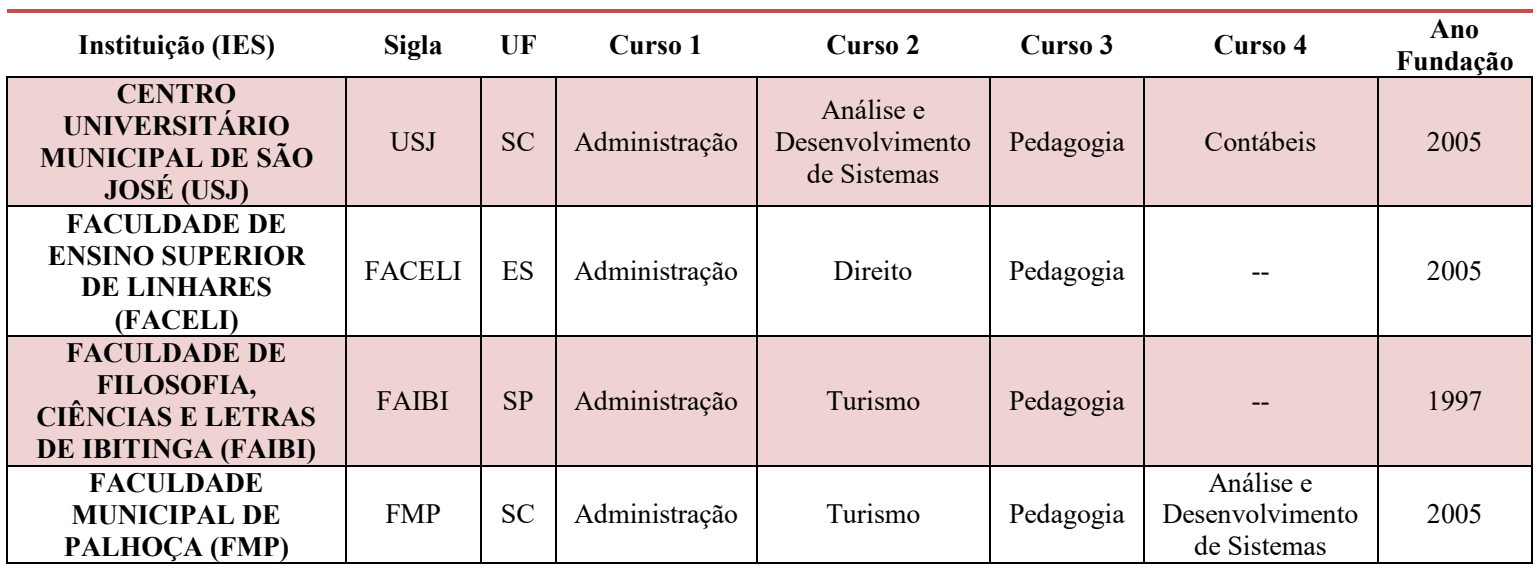

Fonte: Autores (2020).

Diante das informações, observa-se que a gratuidade dos cursos ofertados está relacionada ao ano de fundação dessas instituições, sendo que uma foi criada em 1997 e três em 2005, ou seja, após a CF de 1988.

\subsection{IMES: FACULDADE MUNICIPAL DE PALHOÇA - FMP}

A Faculdade Municipal de Palhoça encontra-se situada na categoria pública e o sistema de ensino é municipal, oferecendo cursos gratuitos em consonância com a LDB n 9.394 e a Resolução 001/2001 do Conselho Estadual de Educação do Estado de Santa Catarina. A Faculdade Municipal de Palhoça (FMP) teve a sua fundação em 25 de outubro de 2005, e sua inauguração efetivada em 20 de abril de 2006, cuja criação foi mediante a Lei Municipal $N^{\circ}$ 2.182. A instituição é uma entidade na categoria de Autarquia, pertencente a 
Administração Indireta do município de Palhoça, conforme Lei Complementar $\mathrm{n}^{\mathrm{o}} 235$, de 22 de novembro de 2016 (FMP, 2020).

A instituição possui um sistema de cotas no qual $90 \%$ das vagas ofertadas são destinadas aos alunos provindos de escolas públicas e que residam no município. As demais vagas (10\%) são ofertadas para alunos residentes em outros municípios (FMP, 2020).

A FMP apresenta sua estrutura funcional formada pela diretoria executiva, uma diretoria administrativa e uma diretoria acadêmica, conforme consta no Regimento Geral da IES. Contudo, a Lei Complementar $\mathrm{n}^{\mathrm{o}} 235$ de 2016 que apresenta a estrutura administrativa do município, contempla a FMP como uma Autarquia e determina outra estrutura: Presidente, Vice Presidente, Diretor Acadêmico e Assessores II, III e IV (PALHOÇA, 2016). O órgão superior deliberativo e consultivo da FMP é o CONFAP.

A estrutura de gestão de pessoas adotada pela instituição demonstra-se centralizada a um departamento subordinado ao diretor administrativo. "Diretoria Administrativa: compete planejar, orientar e coordenar as atividades administrativas, financeiras, de gestão de pessoas, de material, patrimônio, informática e de serviços gerais da Faculdade" (PDI 2019-2023, p. 87).

No que se refere às atividades de recrutamento e seleção, os técnicos administrativos são contratados via processo seletivo realizado pela prefeitura, na qualidade de temporário, ou efetivos realocados na FMP. Quantos aos docentes, a instituição realiza o próprio concurso público e processos seletivos para seleção e contração, que são divulgados por meio de editais no sítio da instituição. Os professores são selecionados considerando a titulação, suas qualificações e produções e a prova didática, buscando averiguar as competências técnicas e comportamentais ao ministrar uma aula teste, que é avaliado por uma banca (FMP, 2020).

Os professores efetivos conquistaram em 2019 a aprovação pela câmara de vereadores a Lei Complementar $\mathrm{n}^{\mathrm{o}} 276$, que instituiu o plano de cargos e salários, permitindo progressão por titulação e aumento salarial por tempo de serviço (PALHOÇA, 2019).

No PDI (2019-2023), apresenta-se como objetivo um programa de aprimoramento individual dos servidores, dentre as metas, destaca-se a propostas de diretrizes a fim de possibilitar a gestão por competências para os servidores da FMP; a potencialização de capacitações e; a implementação da avaliação de desempenho. 


\subsection{IMES: CENTRO UNIVERSITÁRIO MUNICIPAL DE SÃO JOSÉ -USJ}

O Centro Universitário Municipal de São José - USJ é o órgão pertencente à Fundação Educacional de São José, estando, portanto, subordinado a esta, que é a sua mantenedora. Foi criado através da Lei n. 4.27915 de maio de 2005, como instituição de ensino superior, garantida a gratuidade do ensino nos seus cursos regulares de graduação (USJ, 2020). Atualmente, possui aproximadamente 1000 alunos matriculados.

A instituição possui um sistema de cotas, onde $70 \%$ das vagas são destinadas para os alunos oriundos do ensino público no município de São José e 30\% para aqueles egressos do ensino particular, de outras regiões ou que não concluíram todos os anos da vida escolar no ensino público.

O USJ conta com uma estrutura deliberativa e uma executiva, a deliberativa consiste no Conselho Universitário - CONSUNI, e a executiva formada pela Reitoria, Vice-reitoria Acadêmica e Administrativa, Assessorias, Secretaria Acadêmica, Coordenadorias de Cursos e Biblioteca, também conta com Órgãos de Apoio (REGIMENTO GERAL, 2018).

É possível observar que houve um enxugamento na estrutura de cargos ao cruzar as informações contidas na Lei de criação do USJ, Lei nº 4.27915 de maio de 2005, com a aprovação do novo Regimento Geral da IES em 2018, na qual suprime, dentre outros cargos, o cargo de Coordenador de Gestão de Pessoas.

Conforme o Regimento Geral (2018) compete à Reitoria administrar os Recursos Humanos colocados à disposição pela FUNDESJ. Para tanto, tem como apoio um Técnico de Recursos Humanos, com a atribuição de executar as rotinas de departamento de pessoal, atuando no processo de segurança no trabalho e da saúde ocupacional.

O processo de recrutamento e seleção do corpo técnico administrativo ocorre mediante concurso público de provas, sob regime de trabalho regido pela Consolidação das Leis do Trabalho (CLT), conforme Lei n. 4.915 de dezembro de 2009 (SÃO JOSÉ, 2009).

O processo de recrutamento e seleção de professores está condicionado à realização de concurso público de provas e títulos ou processo seletivo externo simplificado, dependendo do tipo de contratação, devendo o contrato de trabalho ser firmado pela mantenedora. Ambos estão sujeitos ao regime celetista (PDI, 2015-2019).

A instituição ainda não tem aprovado um Plano de Cargos e Salários. A Lei n. 5.388 de 07 de maio de 2014, trata da remuneração dos professores de ensino superior conforme titulação, para graduação e pós-graduação. Também possibilitou a progressão docente por 
título, além da admissão em caráter temporário de professor substituto e visitante (SÃO JOSÉ, 2014).

No que diz respeito ao desenvolvimento, o USJ adota como política de qualificação, programas de formação continuada para docentes desde 2006, com cursos e oficinas didáticopedagógicas de atualização e aperfeiçoamento e seminários internos PDI (2015-2019). A instituição concede licença sem vencimentos para que o docente possa participar de cursos de doutorado e mestrado. É um direito do professor receber apoio, por meio de inscrições, diárias e passagens, para participação em eventos científicos e/ou tecnológicos, desde que prévia aprovação pela mantenedora e previsão orçamentária (REGIMENTO GERAL, 2018).

\subsection{IMES: FACULDADE DE ENSINO SUPEIROR DE LINHARES - FACELI}

A Faculdade de Ensino Superior de Linhares - FACELI é uma instituição pública municipal de ensino superior, mantida pela Fundação Faculdades Integradas de Ensino Superior do Município de Linhares, criada pela Lei Municipal № 2.561, de 15 de dezembro de 2005, alterada pela Lei Municipal $n^{\circ}$. 2.681, de 18 de abril de 2007 e credenciada pelo Conselho Estadual de Educação pela Resolução - CEE sob o nº 1.343, de 20 de setembro de 2006. É regulamentada por um Regimento Geral, aprovado pelo Conselho Superior da Faculdade (CONSUP) e pelo Conselho Estadual de Educação do Espírito Santo (FACELI, 2020). A instituição conta com 702 alunos cursando dentre os cursos ofertados, Administração, Direito e Pedagogia (PDI, 2015-2019).

Os serviços prestados pela FACELI reserva em cada processo seletivo $50 \%$ das vagas destinadas aos estudantes que tenham cursado integralmente os ensinos fundamental e médio em escolas públicas ou em escolas particulares mediante benefício de bolsa de $100 \%$ (cem por cento) e possuírem renda familiar per capita igual ou inferior a um salário mínimo e meio; $30 \%$ (trinta por cento) destinados aos que cursaram integralmente o ensino médio e pelo menos um ano de ensino fundamental em escolas públicas, e demais critérios anteriores; e $20 \%$ (vinte por cento) destinados aqueles que cursaram integralmente o ensino médio em escolas públicas ou em escolas particulares mediante benefício de bolsa de 100\% (cem por cento), além dos demais critérios supraelencados (LINHARES, 2019).

A Fundação FACELI conta com uma estrutura administrativa formada pelo Diretor Presidente, Diretor Administrativo e Financeiro e Diretor Acadêmico (ESTATUTO, 2016). A mantida FACELI, conforme dispõe o Regimento Geral (2016), possui sua estrutura 
organizacional delineada por um órgão deliberativo, chamado CONSUP, e mais o executivo (REGIMENTO GERAL, 2016).

O regime jurídico do corpo técnico e docente da FACELI é estatutário, devendo ser aprovados em concurso público de provas e títulos, ou contratados por tempo indeterminado, para atender as excepcionalidades (PDI, 2015-2019).

A admissão de professor regente de classe é feita mediante Edital de seleção (REGIMENTO GERAL, 2016). O Processo Seletivo acontece em duas etapas, prova de títulos (classificatória) e prova de desempenho didático (eliminatória e classificatória).

Em 2016, a Lei Complementar n. 32, foi sancionada e passou a vigorar o Plano de Cargos, Carreiras e Remunerações do Magistério Superior da Fundação FACELI para docentes efetivos ingressantes por meio de concurso público, e em 2017, com a Lei Complementar n. 51, dos servidores públicos da administração direta e indireta do município, dessa forma, contemplando os servidores técnicos-administrativos da FACELI. Permitindo progressões verticais e horizontais, que serão concedidas mediante avaliação de desempenho.

A avaliação de desempenho ocorre anualmente, a partir da identificação e mensuração de conhecimentos, habilidades e atitudes exigidos para o bom desempenho do cargo e cumprimento da missão institucional da FACELI.

No que tange o desenvolvimento de pessoas, tem como meta promover a capacitação continuada dos servidores, realizando convênios com outras instituições de ensino e promovendo eventos internos para a formação continuada (PDI, 2015-2019).

\subsection{IMES: FACULDADE DE FILOSOFIA, CIÊNCIAS E LETRAS DE IBITINGA - FAIBI}

A Faculdade de Filosofia, Ciências e Letras de Ibitinga - FAIBI, conhecida como Faculdade de Ibitinga, tem como mantenedora a Fundação Educacional da Estância Turística de Ibitinga - FEMIB. A FAIBI foi criada em 1997. Em 22/06/2000 obteve o credenciamento institucional, reconhecida através do Parecer no 233/2000 do Conselho Estadual de Educação. Por consequência, a FAIBI iniciou seu funcionamento em 2001, com os cursos de Graduação em Turismo e Graduação em Pedagogia (FAIBI, 2020).

No ano de 2007 foi promulgada a Lei 3.009/07, através da qual o Poder Público Municipal institui a gratuidade nos Cursos de Graduação da FAIBI, momento em que se tornou uma instituição de ensino superior pública municipal (IBITINGA, 2007). Possui cerca de 300 alunos matriculados nos três cursos: administração, pedagogia e turismo. 
A Fundação possui seu órgão executivo formado pela Superintendência, indicado pelo Conselho Curador, Secretário Executivo, nomeado pelo Superintendente, e assessor jurídico. A Faculdade como órgão executivo é estruturada pelo Diretor Geral e Vice Diretor Geral. O órgão deliberativo da faculdade é chamado de Congregação. De acordo com o Regimento, diz que a mantenedora que se responsabiliza pelos serviços administrativos relativos à Contabilidade, Tesouraria, Almoxarifado e Pessoal.

Observa-se que tanto a mantenedora quanto a mantida, não possui uma área específica de Gestão de Pessoas, estando algumas atribuições relativas aos processos de RH centralizadas no Secretário Executivo, cargo pertencente à mantenedora. Conforme o Estatuto da FEMBI compete ao Secretário Executivo avaliar e encaminhar ao Superintendente sobre a necessidade ou não de admissão, dispensa, renovação de contrato do pessoal docente, encaminhado pelas diretorias das mantidas, dentre outras atribuições.

O processo de recrutamento e seleção ocorre mediante concurso público de provas e títulos. Caso não se tenha professor concursado para suprir as demandas, poderá admitir em caráter emergencial e temporário professores colaboradores e visitantes por meio de processo seletivo simplificado (REGIMENTO GERAL, 2003).

O processo de desenvolvimento ocorre por meio de uma Coordenação Pedagógica incumbida de promover os programas de aperfeiçoamento didático-pedagógicos ou científicos aos docentes (REGIMENTO GERAL, 2003).

Quanto à política de benefícios, a Lei 3.584 de 2012 permitiu a concessão de Gratificação por Tempo de Serviço aos servidores públicos municipais lotados na FAIBI, a ser pago obedecendo-se à razão de 5\% (cinco por cento) sobre a referência base do respectivo cargo ou emprego, automaticamente, a cada cinco anos de efetivo exercício no serviço público municipal (IBITINGA, 2007).

\section{ANÁLISE E DISCUSSÕES}

Ao descrever as características das IMES com relação às suas estruturas e como funcionam as atividades da área de gestão de pessoas, foi possível extrair informações que estão em consonância e dissonância entre elas.

Quanto à estrutura legal e a configuração organizacional, a Faculdade Municipal de Palhoça se diferencia das demais IMES, tendo em vista que sua criação pela Lei $\mathrm{n}^{0} 2.182$ de 25 de outubro de 2005 a constituiu como Autarquia mantida pela Prefeitura Municipal de 
Palhoça. Já as demais instituições são mantidas por Fundações, regendo em suas estruturas os Estatutos Fundacionais. As instituições de ensino superior são ditas organizações complexas, pela especialização das atividades e pela execução de tarefas múltiplas, que embora interrelacionadas têm características específicas que as diferem de outras organizações (SOUZA, 2009; SOUZA; KOBIYAMA, 2010).

A FAIBI é a única que não possui o sistema de cotas para o ingresso nos cursos, haja vista que a FMP, o USJ e a FACELI, mesmo que com percentuais diferentes, priorizam o ingresso dos acadêmicos que moram no município ou que estudaram em escolas públicas. Destacando o papel dessas IMES na oportunidade de acesso àqueles que não poderiam adentrar em uma instituição de ensino superior Federal, Estadual ou Particular. Evidencia-se que o impulsionamento para o aparecimento das municipais teve por objetivo o alcance da interiorização da educação, como forma de fomentar a economia local (NEVES, 2018).

O USJ chama a atenção por ser um Centro Universitário representado pela figura do Reitor, enquanto as outras instituições de ensino são enquadradas como Faculdades, gerenciadas pelo Diretor, apresentando-se como Diretor Executivo ou Geral.

Outro ponto que diferencia as IMES é o regime jurídico adotado pelo USJ, sendo a única a adotar o regime celetista na contratação do quadro de pessoal docente e técnico administrativo efetivo e temporário, enquanto as outras três instituições seguem o regime jurídico único do município.

As atividades relacionadas à área de GP do USJ estão vinculadas ao Reitor e auxiliadas por um Técnico de Recursos Humanos do quadro efetivo. Enquanto as outras instituições têm as atribuições de gestão de pessoas ligadas ao Diretor Administrativo ou Secretário Executivo. Tal cenário se ajusta ao que Magalhães et al (2010) relatam, que as IES públicas são semelhantes aos demais órgãos públicos, buscam o controle coletivo sobre as decisões administrativas que os afetam, indicando os próprios pares para realizar parte do trabalho administrativo, e por isso, não se dá a devida atenção para o desenvolvimento da área de Gestão de Pessoas.

A Faculdade FACELI é a instituição que apresenta processos mais estratégicos de gestão de pessoas contemplando o Plano Cargos, Carreiras e Remuneração, tanto para os técnicos administrativos quanto para os docentes, pautado pela Avaliação de Desempenho por Competências, ratificando o entendimento de Camões, Pandoja e Bergue (2010) ao novo modelo de gestão de pessoas, mais estratégico. 
A FMP também possui o plano de carreira aprovado em 2019 pela Lei Complementar $n^{\circ} 276$, contudo, no modelo tradicional, com gratificações e priorizando-se a progressão por tempo de vínculo com a instituição e por titulação. O USJ e a FAIBI não possuem o Plano de Cargos e Carreira, o USJ contempla a Lei n $^{0} 5.388$ de 2014 que autoriza a progressão por titulação dos professores e a FAIBI a Lei 3.584 de 2012 que permite a gratificação por tempo de serviço.

Quanto ao processo de recrutamento e seleção, as IMES realizam o concurso público para o ingresso de pessoal efetivo e o processo seletivo para contratação temporária, utilizando instrumentos semelhantes entre elas. Confirmando o que apregoa a AIMES-SP (2020), que as IMES devem seguir as normas obrigatórias as demais instituições públicas, na contratação por concurso, compras via processo licitatório etc.

O processo de Treinamento e Desenvolvimento foi encontrado na forma de objetivos e metas das IMES em seus PDIs, destaca-se que a FMP propõe um programa de aprimoramento individual dos servidores; já a FACELI na dimensão gestão de pessoas indica a capacitação continuada dos servidores por meio de convênios com outras IES e eventos internos; a FAIBI que apresenta uma Coordenação Pedagógica responsável pela formação continuada dos docentes, vem buscando promover um programa institucional de capacitação docente em caráter permanente; e o USJ afirma que desde 2006 possui programas de formação continuada para docentes, com cursos e oficinas didático-pedagógicas de atualização e aperfeiçoamento e seminários internos. Quando se trata da dimensão humana, a aprendizagem deve ser contínua dos técnicos e docentes, assim como o compartilhamento do conhecimento, possibilitando o aprendizado coletivo (SOUZA, 2009; SOUZA; KOBIYAMA, 2010).

\section{CONSIDERAÇÕES FINAIS}

As instituições de ensino superior municipais nasceram de uma proposta para fortalecer o ensino superior, levando-o para o interior do país e estando mais próximas das necessidades reais da sociedade. Elas configuram estruturas enxutas, apresentando semelhanças e diferenças na maneira como se estruturaram e gerem o quadro de pessoal.

$\mathrm{O}$ objetivo que se construiu para o estudo visou compreender a estrutura e o funcionamento da área de gestão de pessoas das instituições de ensino superior públicas municipais e gratuitas do Brasil. Conforme discorrido no Capítulo 1, introduziu-se a temática, 
justificativa e problematização a respeito dos poucos estudos no âmbito das IMES e também, no tema de interesse ao estudo da área de gestão de pessoas.

Para o alcance do objetivo, no Capítulo 2, contextualizou-se a municipalização do ensino superior no Brasil com referências de autores como Neves (2018); Machado, Diógenes e Bezerra (2014), Magalhães (2013), e a construção da área de gestão de pessoas em instituições de ensino superior públicas para o novo modelo, mais estratégico, buscando compreender de que maneira as IES públicas estão caminhando nesse processo. Deu-se destaque às universidades federais nos estudos de Silva, Alves e Santos (2019); Souza (2009); Souza e Kobiyama (2010); Magalhães et al (2010) e; Camões, Pandoja e Bergue (2010). O decreto-Lei $n^{\circ} 9.991$ de 28 de agosto de 2019, fez com que essas instituições apresentassem mais ações de desenvolvimento da área de gestão de pessoas para uma gestão por competências.

No Capítulo 3, detalhou-se os procedimentos metodológicos nos quais foram utilizados os métodos bibliográficos e documentais, estudando-se os fenômenos por meio de multicascos. Na apresentação dos dados e análise e discussões, Capítulos 4 e 5, foi possível perceber que a FMP é uma autarquia mantida pela prefeitura enquanto das demais IMES são mantidas por fundações educacionais, demonstrando concepções estruturais diferentes na manutenção dessas instituições. O USJ configura como um centro universitário representado pelo reitor e as demais são enquadradas como Faculdades retratadas por seus diretores, abrindo-se a questão sobre a organização e especificidades que um centro universitário requer, delineada pela Resolução do MEC n. 10, de 04 de outubro de 2007, que exige o plano de carreira e a política de capacitação docente implantados.

A FAIBI é a única instituição que não adotou como política o sistema de cotas para o ingresso do aluno na instituição, abrindo-se questões quanto à procura candidato-vaga, características regionais e demográficas.

Assim, consta-se que o objetivo do estudo foi alcançado e a pergunta de pesquisa respondida.

\section{REFERÊNCIAS}

AIMES-SP. O importante papel das Instituições Municipais de Ensino Superior. Disponível em: http://aimessp.com.br/home/aimes-sp/. Acesso em: 03 de abr 2020.

ALBUQUERQUE, L. G.; OLIVEIRA, P. M. Competências ou cargos: uma análise das tendências das bases para o instrumental de recursos humanos. Caderno de Pesquisas em 
Administração, São Paulo, v. 8, n. 4, p. 13-25, 2001. Disponível em: $<$ https://www.academia.edu/25809976/Compet\%C3\%AAncias_ou_cargos_uma_an\%C3\%A1 lise_das_tend $\%$ C3\%AAncias_das_bases_para_o_instrumental_de_recursos_humanos $>$. Acesso em: 20 out 2020.

ARANHA, João Gilberto Torres; SALLES, Denise Medeiros Ribeiro. A evolução da gestão de pessoas nas universidades federais: do patrimonialismo ao estratégico. XV Colóquio Internacional de Gestão Universitária - CIGU: Argentina, dez 2015. Disponível em: https://repositorio.ufsc.br/bitstream/handle/123456789/136019/101_00118.pdf?sequence=1. Acesso em: 09 abr de 2020.

BOENTE, Alfredo; BRAGA, Gláucia. Metodologia científica contemporânea: para universitários e pesquisadores. Rio de Janeiro: Brasport, 2004.

BURIGO, C. C. D; SOUZA, G. M; RIBEIRO, P. Formação no Contexto da Gestão por Competências. $1^{\mathrm{a}}$ ed. Dados eletrônicos. Florianópolis: UFSC, 2019.

CARVALHO, Julia. O enfrentamento da pandemia pelas universidades federais. Redação JC. USP, set 2020. Disponível em:

http://www.jornaldocampus.usp.br/index.php/2020/09/o-enfrentamento-da-pandemia-pelasuniversidades-

federais/\#: :text=Dist\%C3\%A2ncia\%20e\%20demora.\&text=No\%20dia $\% 2018 \% 20 \mathrm{de} \% 20 \mathrm{ma}$ r\%C3\%A7o,adotado\%20essa\%20modalidade\%20de\%20ensino. Acesso em: 18 out 2020.

CERVO, Amado Luiz; BERVIAN, Pedro Alcino; DA SILVA, Roberto. Metodologia científica. 6. ed. São Paulo: Pearson Prentice Hall, 2007.

CRESWELL, J. W. W. Projeto de pesquisa: métodos qualitativo, quantitativo e misto. 2. ed. Porto Alegre: Bookman, 2010.

E-MEC. Cadastro Nacional de Cursos e Instituições de Educação Superior Cadastro eMEC. Relatório de Consulta Avançada. Disponível em: http://www.E-Mec.gov.br/. Acesso em: 06 mar 2020.

FACELI. Estatuto Fundação FACELI. 2016. Disponível em:

http://faceli.edu.br/admin/arquivos/arquivos_26_09_2013_013847/arquivos_03.pdf. Acesso em: 27 abr de 2020.

FACELI. PDI 2015-2019. Disponível em:

http://faceli.edu.br/admin/arquivos/arquivos_26_09_2013_013847/arquivos_06.pdf. Acesso em: 27 abr de 2020.

FAIBI. Regimento Geral. 2003. Disponível em: http://faibi.com.br/arquivos/regimentointerno/faibi/faibi-regimento.pdf. Acesso em: 25 set 2020.

GUIMARÃES, José Luiz. Instrumentalização Política dos Convênios de Municipalização do Ensino em São Paulo: Algumas Evidências. RAP. Rio de Janeiro: FGV, jul/set 1993. 
IBITINGA, Lei $\mathrm{n}^{\circ}$ 3.009, de 19 de setembro de 2007. Altera as Leis municipais 2.247, de 20 de agosto de 1997, e 2.252, de 06 de outubro de 1997, que tratam da Fundação Educacional Municipal de Ibitinga - FEMIB. 2007. Disponível em: http://faibi.com.br/arquivos/femib/estatuto/femib-estatuto-19-09-2007-3009.pdf. Acesso em: 30 out 2020 .

LAKATOS, Eva Maria; MARCONI, Marina de Andrade. Técnicas de pesquisa: planejamento e execução de pesquisas, amostragens e técnicas de pesquisas, elaboração, análise e interpretação de dados. 7. ed. São Paulo: Atlas, 2013.

LINHARES, Lei ${ }^{\circ}$ 3.902, de 17 de dezembro de 2019. Dispõe sobre o ingresso de alunos na faculdade de ensino superior de linhares - FACELI e dá outras providências. Disponível em: http://legislacaocompilada.com.br/linhares/Arquivo/Documents/legislacao/html/L39022019.h tml. Acesso em 21 out de 2020.

LINHARES, Lei $\mathrm{n}^{\circ} 3.767$, de 24 de setembro de 2018. Institui a extensão da carga horária ao magistério superior da fundação faculdades integradas de ensino superior do município de linhares - fundação FACELI, e dá outras providências. Disponível em: http://legislacaocompilada.com.br/linhares/Arquivo/Documents/legislacao/html/L37672018.h tml. Acesso em 21 out de 2020.

LINHARES, LEI complementar $n^{\circ} 51$, de 29 de dezembro de 2017 . Dispõe sobre o plano de cargos, carreiras e remunerações dos servidores públicos da administração direta do poder executivo, das autarquias e das fundações do município de Linhares. Disponível em:http://legislacaocompilada.com.br/linhares/Arquivo/Documents/legislacao/html/C512017. html. Acesso em: 21 de out de 2020.

LINHARES, Lei complementar $\mathrm{n}^{\mathrm{o}}$ 32, de 09 de março de 2016._ Dispõe sobre o plano de cargos, carreiras e remunerações do magistério superior da fundação faculdades integradas de ensino superior do município de Linhares - Fundação FACELI. Disponível em: http://legislacaocompilada.com.br/linhares/Arquivo/Documents/legislacao/html/c322016.html \#a4_VI_36_2016. Acesso em: 30 de out de 2020.

MACHADO, Mikeully Meire de Andrade; DIÓGENES, Suziane Araújo; BEZERRA, José Eudes Baima. Descentralização, participação e gestão democrática na educação brasiLeira: Primeiros Achados. IV Seminário CETROS, Neodesenvolvimentismo, Trabalho e Questão Social. Fortaleza/CE, 2013. Disponível em: http://www.uece.br/eventos/seminariocetros/anais/trabalhos_completos/69-18026-08072013163328.pdf. Acesso em: 09 abr de 2020.

MAGALHÃES, Elenice Maria de; OLIVEIRA, Adriel Rodrigues de; CUNHA, Nina Rosa da Silveira; LIMA, Afonso Augusto Teixeira de Freitas de Carvalho; CAMPOS, Daniela Cristina da Silveira. A política de treinamento dos servidores técnico-administrativos da Universidade Federal de Viçosa (UFV) na percepção dos treinados e dos dirigentes da instituição. Rio de Janeiro: RAP, jan/fev 2010. 
MARRAS, Jean Pierre. Administração de Recursos Humanos: do operacional ao estratégico. São Paulo: Saraiva, 2016.

MOTA, A. B. R. A História da Municipalização do Ensino no Brasil. Unicamp, 2007. Disponível em:

http://www.histedbr.fe.unicamp.br/acer_histedbr/jornada/jornada7/_GT2\%20PDF/A\%20HIS T\%D3RIA $\% 20 \mathrm{DA} \% 20 \mathrm{MUNICIPALIZA} \% \mathrm{C} 7 \% \mathrm{C} 3 \mathrm{O} \% 20 \mathrm{DO} \% 20 \mathrm{ENSINO} \% 20 \mathrm{NO} \% 20 \mathrm{BRA}$ SIL.pdf. Acesso em: 03 de abr 2020.

NEVES, Rodrigo Santos. Instituições Municipais de Ensino Superior. Academia.edu, 2018. Disponível em:

https://www.academia.edu/37117538/Institui\%C3\%A7\%C3\%B5es_municipais_de_ensino_su perior. Acesso em: 09 mai 2020.

PANTOJA, Maria Júlia; CAMÕES, Marizaura R. de Souza; BERGUE, Sandro Trescastro. Gestão de Pessoas: bases teóricas e experiências no setor público. Brasília: ENAP, 2010.

RIBEIRO, Elizabeth; RANGEL, Márcia; ARRUDA, Rosilda; PINTO, Lorene; SOUZA, Gisélia. Relato de experiência - formação profissional em gestão por competências no setor público na UFBA: a relevância da abordagem metodológica e pedagógica do blendedlearning.

ROCHA, Guilherme Busch; SHINYASHIKI, Gilberto Tadeu; PASSADOR, Cláudia Souza. Gestão de Pessoas em uma Universidade Pública BrasiLeira: conflito na Mudança do Modelo de Gestão. EnANPAD, 2012. Disponível em:

http://www.anpad.org.br/admin/pdf/2012_EOR919.pdf. Acesso em: 14 de abr 2020.

SÃO JOSÉ, Lei no 5388, DE 07/05/2014. Altera a Lei no 4491, de 04 de janeiro de 2007, a Lei $n^{\circ}$ 4915, de 17 de dezembro de 2009 e a Lei no 4955, de 07 de maio de 2010, e dá outras providências. Disponível em: https:/Leismunicipais.com.br/a/sc/s/sao-jose/Leiordinaria/2014/538/5388/Lei-ordinaria-n-5388-2014-altera-a-Lei-n-4491-de-04-de-janeiro-de2007-a-Lei-n-4915-de-17-de-dezembro-de-2009-e-a-Lei-n-4955-de-07-de-maio-de-2010-eda-outras-providencias. Acesso em: 30 de out de 2020.

SÃO JOSÉ, Lei n ${ }^{\circ}$ 4915, de 17 de dezembro de 2009. Dispõe sobre a criação de empregos no quadro de pessoal da administração indireta e dá outras providências. 2009.

Disponível em: https://Leismunicipais.com.br/a1/sc/s/sao-jose/Lei-

ordinaria/2009/491/4915/Lei-ordinaria-n-4915-2009-dispoe-sobre-a-criacao-de-empregos-noquadro-de-pessoal-da-administracao-indireta-e-da-outras-providencias. Acesso em: 20 out 2020 .

SILVA, Narbal. Gestão de pessoas por competências: ideias norteadoras, limites e possibilidades. Universidade Federal de Santa Catarina - UFSC.

SOUZA, Irineu Manoel de. Gestão das Universidades BrasiLeiras: uma abordagem fundamentada na Gestão do Conhecimento. 2009. 01 v. Tese (Doutorado) - Curso de Engenharia do Conhecimento, Departamento de Engenharia e Gestão do Conhecimento, Universidade Federal de Santa Catarina, Florianópolis, 2009. 
SOUZA, Irineu Manoel de; KOBIYAMA, Adriana Regina Costa Espíndola. Políticas de Gestão de Pessoas para as Universidades Federais. X Colóquio Internacional sobre Gestión Universitaria en América del Sur, 2010. Disponível em:

https://core.ac.uk/download/pdf/30378002.pdf. Acesso em: 04 de abr 2020.

TACHIZAWA, Takeshy; FERREIRA, Victor Cláudio Paradela; FORTUNA, Antônio Alfredo Mello. Gestão com pessoas: uma abordagem aplicada às estratégias de negócios. Rio de Janeiro: FGV, 2006. 